\title{
UMA LEITURA DAS CIÊNCIAS HUMANAS E SOCIAIS EM PROSPECTIVA A PARTIR DE THEODOR W. ADORNO *
}

\author{
A prospective reading of the Human and Social Sciences based on Theodor \\ W. Adorno
}

\author{
Fábio César Junges ** \\ Antonio Escandiel de Souza *** \\ Vânia Maria Abreu de Oliveira ****
}

Resumo: Na intenção de lançar luzes sobre a atualidade das Ciências Humanas e Sociais, o presente ensaio apresenta a leitura crítica que Theodor W. Adorno faz das Ciências Humanas e Sociais em meados do século XX. Gestado em meio à segunda guerra mundial, o pensamento de Adorno se constitui num dos principais referenciais para pensar o lugar e o papel das Ciências Humanas e Sociais hoje. Diante disso, este ensaio defende a tese de que sua atualidade se encontra na crítica determinada das atuais condições sociais vigentes, enquanto dilatação das fissuras históricas produzidas pelos mais variados sistemas sociais, políticos e culturais.

Palavras-chave: Fissuras históricas. Atualidade. Interpretação. Negatividade. Epistemologia audaciosa.

\footnotetext{
* Artigo recebido em 19/08/2019 e aprovado para publicação em 13/05/2020

** Doutorado em Teologia pela Faculdades EST, São Leopoldo, RS. Pós-Doutorado em Educação nas Ciências pela Universidade Regional do Noroeste do Estado do Rio Grande do Sul (UNIJUÍ). Atualmente é Pós-Doutorando em Práticas Socioculturais e Desenvolvimento Social pela Universidade de Cruz Alta (UNICRUZ), RS.

*** Doutorado em Linguística Aplicada pela Universidade Federal do Rio Grande do Sul (UFRS). Professor da Universidade de Cruz Alta (UNICRUZ), vinculado ao Programa de Pós-Graduação Práticas Socioculturais e Desenvolvimento Social.

**** Doutorado em História pela PUCRS. Mestrado em História pela PUCRS. Graduação em História pela UNIJUÍ. Docente da Universidade de Cruz Alta (UNICRUZ), Cruz Alta, RS, Brasil, vinculada ao Programa de Pós-Graduação em Práticas Socioculturais e Desenvolvimento Social.
} 
Abstract: With the intention of shedding light on the current relevance of the Human and Social Sciences, this essay presents Theodor W. Adorno's critical reading on these Sciences in the middle of the XX century. Adorno's thinking, developed in the midst of World War II, is one of the main references for understanding the place and role of the Human and Social Sciences today. Thus, this essay defends the thesis that their current relevance lies in the determined criticism of the current social conditions, as a dilation of the historical fissures produced by the most varied social, political and cultural systems.

Keywords: Historical fissures. Present. Interpretation. Negativity. Audacious epistemology.

\section{Introdução}

$\mathrm{N}$ o presente artigo é realizada uma interpretação do pensamento de Theodor W. Adorno em prospectiva, no sentido de pensar a atualidade das Ciências Humanas e Sociais, ou seja, na própria interpretação do seu pensamento está contida a intenção de compreender a função e o papel das Ciências Humanas e Sociais hoje. A crítica de Adorno às Ciências Humanas Sociais, elaborada em meio aos destroços da segunda guerra mundial, procurando encontrar vestígios de esperança em meio à desesperança, é radical, uma vez que afirma que estes projetos de pensamento se encontram sustentados na ilusão da "capacidade do pensamento se apoderar da totalidade do real" (ADORNO, 2003f, p. 325). ${ }^{1}$ Sua crítica, contudo, não é o ponto de chegada de seu pensamento, pois da negatividade levada a sua completude poderão irradiar-se perspectivas que apontam para a função das Ciências Humanas e Sociais na atualidade.

Nas Ciências Humanas e Sociais o delírio de encontrar e acessar a realidade em si mesma é milenar. Perpetuou-se, historicamente, a possibilidade da realidade se coadunar ao pensamento, promovendo a ideia de que existe um atrás-mundo que pode ser acessado por meio de um método rigoroso colocado em prática pelo sujeito racional. Acreditava-se que o conceito não somente captura a realidade, mas que pudesse desenvolvê-la a partir de si mesmo. Nas Ciências Exatas, por sua vez, esse delírio talvez seja ainda mais forte, quando se acredita na neutralidade do sujeito sobre o objeto investigado. De qualquer sorte, gradativamente nas Ciências Humanas e Sociais se percebe que não há como pisar fora do chão da interpretação. Pretender o contrário é como fugir da própria sombra. Caem, neste sentido, os véus dos possíveis detrás-mundos que supostamente se escondem sob a realidade.

${ }^{1}$ ADORNO, Theodor W. Die Aktualität der Philosophie. ADORNO, Theodor W. Gesammelte Schriften, v. 4. Berlim: Suhrkamp Verlag e Digitale Bibliothek, 2003, p. 325. 
Portanto, a análise da recente história das Ciências Humanas e Sociais na perspectiva de Adorno é condição para se colocar a pergunta pela sua atualidade. É da análise dos resultados das perguntas e respostas colocadas e dadas historicamente que advém a problemática aqui levantada: as Ciências Humanas e Sociais ainda são absolutamente atuais? Decorre dessa pergunta a expectativa que salte alguma faísca de esperança para as Ciências Humanas e Sociais em meio a toda a radicalidade crítica. Este desenvolvimento exige a explicitação da tese central de toda a argumentação: a ideia fundamental das Ciências Humanas e Sociais é a interpretação. O artigo, portanto, desenvolve esta tese no sentido de apresentar uma perspectiva reflexiva para as Ciências Humanas e Sociais que não danifica a realidade das coisas mesmas, por meio de um olhar audacioso para essa realidade danificada e que, pela própria interpretação do pensamento do Adorno, apresenta perspectivas para a atualidade de tais ciências.

\section{As Ciências Humanas e Sociais e as brechas da história}

A leitura das Ciências Humanas e Sociais em prospectiva, a ser realizada neste ensaio, toma como ponto de partida o texto A Atualidade da Filosofia, publicado, por Adorno, em 1931. Uma objeção pode ser aqui colocada sobre a opção de neste tópico se fazer uso de um texto de 1931, quando se poderia partir de obras mais densas e maduras de Adorno, como é o caso de Dialética Negativa, publicada em 1966, o que exige uma justificativa. Tiedemann, principal editor das obras de Adorno, considera seus primeiros escritos filosóficos como "ainda apenas uma promessa, mas uma promessa que o autor cumpriu por meio de suas obras posteriores". ${ }^{2}$ De fato, em suas obras posteriores, enquanto reflexão mais madura, Adorno cumpre o que se colocava apenas de modo programático no texto de 1931. Maior expressão deste desenvolvimento é a própria obra Dialética Negativa.

Há mais outro texto de Adorno que pode ser lembrado como demonstração de sua "antecipação em sonhos". Em julho de 1932, um ano após seu discurso programático como professor não titular, Adorno tem a oportunidade de realizar uma conferência, intitulada A Ideia de História Natural. ${ }^{3}$ Nesta conferência, Adorno intenta "superar a usual antítese entre natureza e história", ${ }^{4}$ que entendia a história como uma entrelaçada oposição entre

\footnotetext{
2 TIEDEMANN, Rolf. Editorische Nachbemerkung. In: ADORNO, Theodor W. Gesammelte Schriften, v. 1. Berlim: Suhrkamp Verlag e Digitale Bibliothek, 2003, p. 384.

${ }^{3}$ ADORNO, Theodor W. Die Aktualität der Philosophie. ADORNO, Theodor W. Gesammelte Schriften, v. 4. Berlim: Suhrkamp Verlag e Digitale Bibliothek, 2003, p. 345-365.

${ }^{4}$ Ibid. p. 345.
} 
mito proto-histórico e novidade histórica, defendendo a tese de que "a história é mítica em grande medida, precisamente onde é histórica em grande medida". ${ }^{5}$ Para Adorno, não se compreende corretamente a natureza quando se pensa ela como mera facticidade. Também não se pode pensar a história como sendo simplesmente história universal do espírito, como processo de progresso, de evolução, tal como se tinha feito na ilustração.

Esta tese de 1932 é uma antecipação da tese defendida pelo autor juntamente com Horkheimer na obra Dialética do Esclarecimento, bem expresso no problema por eles colocado: "o que nos propuséramos era, de fato, nada menos do que descobrir por que a humanidade, em vez de entrar em um estado verdadeiramente humano, está se afundando em uma nova espécie de barbárie" (ADORNO; HORKHEIMER, 2003, p. 11). ${ }^{6}$ Neste sentido, Adorno se coloca como herdeiro da Aufklärung, mas também se distancia dela, do mesmo modo como se revela herdeiro de Hegel e Bloch e, ao mesmo tempo, se distancia dos mesmos. Portanto, a percepção do próprio Adorno de que seu pensamento se moveu numa espécie de "antecipação em sonhos" não pode ser negligenciada, pois ele "permaneceu fiel a seu programa".

Entre outros aspectos de seu pensamento antecipado em 1931, Adorno permaneceu fiel à ideia de que o pensamento não abarca a totalidade do real, exigindo a renúncia de um pensamento bem ordenado. Em consequência, a renúncia de que as coisas são dotadas de sentido e de intencionalidade exige a disposição teórica de olhar a vida mesma, ouvindo aquilo que ela mesma gostaria de esconder ou de expressar. Isto significa, em primeiro lugar, a disposição de trabalhar com o fragmentado, com o inconcluso, com o destituído de sínteses finais, pois o mundo das coisas é um mundo danificado, marcado por seu caráter fragmentário em forma de "cacos" que requerem ser olhados. Trazer esse mundo danificado para dentro da reflexão para, com e a partir dele pensar a vida, parece resumir a atitude de pensamento que conduz toda obra de Adorno. Ao mesmo tempo, é este o desafio do presente tópico do ensaio: apresentar a tarefa das Ciências Humanas e Sociais como pensar a vida a partir dela mesma, a partir de seus próprios entrelaçamentos, o que requer uma epistemologia audaciosa.

O atual estado social, político e econômico revela um mundo, enquanto experiência e interpretação, que exige a expressão de um conhecimento audacioso. É na realidade experienciada, tão crua quanto viva como no holocausto de Auschwitz mostrado por Adorno, que a desesperança surge

\footnotetext{
${ }_{6}^{5}$ Ibid. p. 364.

${ }^{6}$ ADORNO, Theodor W; HORKHEIMER, Max. Dialektik der Aufklärung. In: ADORNO, Theodor W. Gesammelte Schriften, v. 4. Berlim: Suhrkamp Verlag e Digitale Bibliothek, 2003, p. 11. 7 WIGGERSHAUS, Rolf. Escola de Frankfurt: história, desenvolvimento teórico, significação política. Rio de Janeiro: Difeel, 2002, p. 126.
} 
como elemento fontal de pensar e praticar as Ciências Humanas e Sociais enquanto libertadoras, que tenham a verdade como mote. A realidade danificada é o lugar de partida de um pensamento audacioso, enquanto interpretação das experiências concretas de mundo, seu sofrimento e sua desesperança, sem se esconder em pensamentos capazes de ordenar toda a vida humana, sem, contudo, ouvir os clamores da vida danificada. Trata-se de um modo de pensamento que encontra a esperança na própria desesperança.

As Ciências Humanas e Sociais, quanto mais profundamente penetram no âmago da vida na tentativa de chegar a uma determinada essência que pudesse um dia ser desvelada, tanto mais distantes permanecem da vida mesma, daquilo que de fato importa, que poderia ser visto pelas ideias mais simples do cotidiano. O distanciar-se do modo como as coisas são torna as Ciências Humanas e Sociais suspeitas, pois, assim, não são capazes de ver a vida na sua simplicidade, na sua trivialidade. $O$ incidir de uma luz crua sobre a verdade manifesta a suspeita das Ciências Humanas e Sociais, que têm como pretensão desvelar a essência das coisas mesmas, exigindo uma reflexão audaciosa.

"A reflexão audaciosa busca conquistar para o pensamento aquilo que a reflexão cautelosa dele eliminou, inocência". ${ }^{8}$ Não poucas vezes o olhar das Ciências Humanas e Sociais permaneceu afastado do passageiro, do fugaz, do culturalmente feio, do rudimentar, do simples, sendo a botija, para Adorno, um destes exemplares. Numa botija abandonada não se encontra nada de espetacular e belo segundo os padrões da cultura vigente. Mas é justamente isto que precisa ser considerado pela reflexão audaciosa das Ciências Humanas e Sociais. Trata-se de olhar para aquilo que a reflexão cautelosa justamente eliminou. Preservar o olhar no que foi agregado na velha botija ao longo de sua história se apresenta como a utopia epistemológica de Adorno. Isso coloca o pensamento de Adorno (2003c, p. 235) "em contato com o inferior, separado da cultura, aquilo que é abertamente esculachado".

Este olhar, contudo, não se dá de qualquer modo. Não é tarefa das Ciências Humanas e Sociais simplesmente dissecar a botija e ver o que se encontra nela; também não é sua função extrair uma ontologia de dentro de sua barriga. A epistemologia audaciosa se volta para aquilo que a reflexão cautelosa eliminou como parte da tarefa das Ciências Humanas e Sociais. Nesta nova postura epistemológica, o sujeito não poderá impor a sua perspectiva de leitura da realidade enquanto tal, mas permitir que ela, enquanto linguagem de coisa, expresse e ao mesmo tempo esconda aquilo

${ }^{8}$ ADORNO, Theodor W. Noten zur Literatur: Henkel, Krug und frühe Erfahrung. In: ADORNO, Theodor W. Gesammelte Schriften, v. 11. Berlim: Suhrkamp Verlag e Digitale Bibliothek, 2003, p. 565. 
que não gostaria de expressar. Compreender a coisa em sua linguagem própria seria o suficiente para ser compreendido. Mas justamente isto foi eliminado pelo pensar das Ciências Humanas e Sociais.

As Ciências Humanas e Sociais, não poucas vezes, além de o sujeito impor a sua perspectiva de compreensão, não permitindo a coisa, em sua linguagem de coisa, expressar-se, não permitiram que a coisa não dissesse absolutamente nada. Ou seja, procurou-se dissecar ao máximo as coisas e extrair absolutamente tudo o que parecia necessário. Permitir que a coisa fale e esconda o que não gostaria de expressar é, portanto, a utopia do pensamento de Adorno. Utopia porque na história das Ciências Humanas e Sociais isto ainda está longe de se realizar. Realizando-se, contudo, a realidade finalmente seria diferente do que sempre foi determinada a ser. Surgiria, enfim, uma nova cor no acinzentado da história das Ciências Humanas e Sociais. Permitir a manifestação de uma cor diferente, eis o ideal da reflexão audaciosa concebida por Adorno.

Neste sentido, uma das principais influências que Adorno recebe de Bloch está na nova relação que este estabelece para com os objetos. Os objetos, antes de estarem à disposição do sujeito, são condições para que o próprio sujeito se reabilite. A primazia conferida por Adorno ao objeto é possibilidade do próprio sujeito que faz ciência novamente se encontrar. Ao objetivar a realidade em que se encontra, o sujeito, que faz parte desta mesma realidade, também se objetivou. $\mathrm{O}$ único modo de se reabilitar, enquanto sujeito, é devolvendo ao objeto a sua condição de objeto, sem ser novamente enclausurado em esquemas de dominação e de objetivação. Em outras palavras, o mundo dos objetos é marcado por uma fartura de conteúdo que já não pode ser visto nem se expressar devido à clausura em que foi colocado.

"Entregar-se ao objeto equivale a fazer justiça a seus momentos qualitativos" (ADORNO, 2003e, p. 44). Historicamente, as Ciências Humanas e Sociais eliminaram a qualidade do objeto em função da sua quantidade. Em sua capacidade de diferenciação de objetos e na reunião dos quantitativos semelhantes, estes foram distinguidos dos diferentes. A perspectiva que Adorno propõe olha para o diferenciado, para aquele aspecto mais ínfimo que escapa do conceito. Trata-se de uma crítica ao modo analógico de fazer ciência que configura as coisas dentro de um sistema de pensamento quantitativo. A justiça aos momentos qualitativos do objeto poderá ser feita na medida em que se assumir que conceito e realidade possuem a mesma essência contraditória. Acontece que, em sua tentativa de buscar o fundamento do conhecimento no sujeito, foi expulsa a dimensão histórica do pensamento.

No enclausuramento da realidade em determinados esquemas subjetivos, o ser humano se tornou vítima de sua própria ação. Na objetivação da realidade, deixou de perceber que ela é e pode ser muito mais do que 
aquilo a que foi condicionada e submetida a ser. Como consequência, o próprio sujeito se encontra preso aos limites que ele próprio se impôs ao encapsular a realidade em esquemas subjetivos prévios. Decorre que por mais que as experiências subjetivas parecem se fazer próprias e individuais em cada sujeito, estas não passam de aparências, uma vez que o sujeito não consegue mais perceber possibilidades de realização naquilo que se apresenta de modo diferenciado. O sujeito, portanto, vive a ilusão de que faz experiências individuais e próprias, especialmente por força sugestiva da indústria cultural, mas que na verdade não passam de uma mera ilusão.

Ao objetivar a realidade, o próprio sujeito se tornou objeto. Somente a reconciliação com a realidade poderá devolver a subjetividade ao sujeito objetivado. Quando se afirma que determinado objeto é de tal modo necessariamente, são rejeitadas potencialmente todas as demais formas que o objeto poderia ter. A violência do pensamento em relação à realidade opera também violência contra o próprio sujeito. "A liberdade imperiosa do sujeito, também procura obter do objeto aquilo que se perdeu por meio de sua transformação em objeto".$^{9} \mathrm{O}$ sujeito poderá se encontrar como sujeito na medida em que devolver ao objeto o que lhe é próprio, a sua liberdade.

O sujeito não é eliminado na constituição do conhecimento. Pelo contrário, "em uma oposição brusca em relação ao ideal de ciência corrente, a objetividade de um conhecimento dialético precisa mais, não de menos sujeito. Senão, a experiência filosófica definha".$^{10} \mathrm{O}$ que importa é a experiência de um sujeito que possui corpo, portanto, historicidade, fragilidade, incompletude. A ideia de experiência aponta os limites das Ciências Humanas e Sociais que, não raras vezes, compreenderam o conhecimento como projeção do sujeito cognoscente sobre o objeto cognoscível. O sujeito que conhece o objeto é um ser empiricamente existente, transitório, situado, um corpo humano que se sente parte da natureza e não uma categoria abstrata sem vida e sem sentimentos. O ser humano é constituído antes de ser constituinte. Possui um corpo histórico e temporalmente situado. Somente uma liquidação do idealismo por uma crítica imanente poderá revelar uma nova compreensão e relação entre as pessoas e destas para com as coisas.

Se para o pensamento moderno a natureza precisava ser colocada na mesa de tortura, para Adorno e para Bloch é necessário uma nova relação para com ela, a fim de que natureza e sujeito sejam reabilitados. O que é capaz de restabelecer uma práxis social capaz de romper este círculo vicioso? As Ciências Humanas e Sociais, de modo especial, terão que privilegiar

\footnotetext{
${ }^{9}$ ADORNO, Theodor W. Negative Dialektik. In: ADORNO, Theodor W. Gesammelte Schriften, v. 6. Berlim: Suhrkamp Verlag e Digitale Bibliothek, 2003, p. 3.

${ }^{10}$ ADORNO, Theodor W. Negative Dialektik. In: ADORNO, Theodor W. Gesammelte Schriften, v. 6. Berlim: Suhrkamp Verlag e Digitale Bibliothek, 2003, p. 42.
} 
as fissuras que escapam do enclausuramento do modelo social que tudo recobre, especialmente o que é de pouco valor comercial. Há que se olhar para aqueles que não estão dentro deste círculo: desempregados, estudantes, marginais, delinquentes, pessoas enfermas e insanas. Seguindo a lógica de Adorno e dos demais frankfurtianos, são estas pessoas, assim como os artistas autênticos, ${ }^{11}$ que têm condições de algum modo de romper com este círculo de objetivação do sujeito ao objetivar a realidade. É com estas pessoas que há possibilidade de se romper o círculo vicioso. Quanto mais a pessoa está desprendida da obrigação privada, mais livre é a sua possibilidade de romper a mesmice totalizante da produção.

A libertação do ser humano da clausura em que ele mesmo se colocou na dominação dos objetos é a tarefa do pensamento. Trata-se de uma incondicional confiança recíproca entre seres humanos e coisas. Isso significa uma relação diferenciada com o objeto, implicando também uma nova relação com os sujeitos que se coisificaram juntamente com os objetos. Acontece, no entanto, que a clausura é tão ampla que, de modo geral, parece que as coisas são necessariamente como atualmente são. Mueller vai denominar este enclausuramento de "recalcamento do utópico". ${ }^{12} \mathrm{O}$ aparato social encontra-se de tal modo endurecido que dificilmente as pessoas conseguem ver o mundo de modo diferente do que ele se apresenta diante dos seus olhos. A condição social vigente parece ser a única forma possível de organização social. Contudo, apesar de todo recalcamento, vez por outra abrem-se algumas fissuras não totalmente recobertas pelo sistema.

Minha tese a esse respeito seria a seguinte: que, no mais íntimo, todas as pessoas, admitindo isto a si próprias ou não, sabem: seria possível, poderia ser diferente. Elas poderiam, não só viver sem fome e provavelmente sem medo, mas também como livres. Ao mesmo tempo, porém, e em todo o mundo, o aparato social se endureceu de tal modo em relação a elas que aquilo que está diante dos seus olhos como possibilidade palpável, como a evidente possibilidade de realização, se apresenta a elas como radicalmente impossível. ${ }^{13}$

O recalcamento da utopia é evidente. Mas esta não é a última palavra. As pessoas, mesmo não admitindo para si mesmas, mesmo juradas ao mundo como ele é, sabem que seria possível de a realidade ser diferente. Neste caso, restam possibilidades para o pensamento enquanto negação determinada da situação enquanto tal. E esta, ao ser revelada como falsa, aponta para aquilo que poderia vir-a-ser. Uma das formas de fugir do en-

\footnotetext{
${ }^{11}$ No Brasil, é possível citar alguns dentre tantos outros: Adélia Prado, Manoel de Barros, Cecília Meirelles, Chico Buarque.

12 MUELLER, Ênio Ronald. Filosofia à sombra de Auschwitz: um dueto com Adorno. São Leopoldo: Sinodal/EST, 2009, p. 97.

${ }^{13}$ ADORNO apud MUELLER, Ênio Ronald. Filosofia à sombra de Auschwitz: um dueto com Adorno. São Leopoldo: Sinodal/EST, 2009, p. 97.
} 
clausuramento da realidade, enquanto negação dela, é o ato de brincar ${ }^{14}$. O brincar é uma forma determinada de negação daquilo que meramente é. Hegel já dizia que o ato de comprar flores é uma forma determinada de negação do sistema. O brincar e o comprar flores são subversivos ao criarem, mesmo que por instantes, uma realidade que não se rege pelas determinações e realizações vigentes. Conforme o poeta Manoel de Barros, "as coisas que não têm nome são mais pronunciadas por crianças". ${ }^{15}$

\section{Da negatividade radical à atualidade das Ciências Humanas e Sociais}

Adorno não procura vestígios positivos da esperança. Pelo contrário, reflete sobre as não realizações da utopia. Não vê vestígios de esperança, pois a sombra de Auschwitz tudo encobre. Benjamin, de modo similar, aponta para a história da realização humana como um amontoado de ruínas sobre ruínas. Pode-se dizer que enquanto Bloch (2005) olha para o futuro e vê nele vestígios de realização da utopia, Adorno, tal como o Angelus Novus, ${ }^{16}$ vê um amontoado de ruínas que se estendem até o céu. Ao invés de mirar os seus olhos para o futuro, Adorno os mantêm na catástrofe, com a intenção de "acordar os mortos e juntar os fragmentos", ${ }^{17}$ na convicção de que, caso haja alguma esperança, esta inicia vendo e indicando a catástrofe.

Para Adorno, a única forma de positividade para as Ciências Humanas e Sociais "encontra-se essencialmente na negação determinada, na negação determinada daquilo que meramente é e que, com isso, ao se concretizar como falso, ao mesmo tempo sempre aponta para aquilo que deve ser". ${ }^{18}$ Na negação determinada, a esperança poderá se amalgamar em seu contrário, como Adorno reflete ao final de Minima Moralia: "a negatividade levada à completude, uma vez mirada bem nos seus olhos, se amalgama em escrita inversa do seu contrário".$^{19}$ A recusa de nomear a positividade é uma exigência do próprio materialismo. Se há alguma positividade, esta se encontrará na negatividade levada a sua completude.

\footnotetext{
${ }^{14} \mathrm{Na}$ perspectiva de Michel de Certeau, a invenção do cotidiano se dá pela "arte de fazer", "astúcias sutis", "táticas de resistência", que vão alterando os objetos e os códigos, e estabelecendo uma reapropriação do espaço e do uso ao jeito de cada um (CERTEAU, Michel de. A invenção do cotidiano: artes de fazer. Petrópolis: Vozes, 1994).

${ }^{15}$ BARROS, Manoel de. Uma didática da invenção, 2015 s/p. Disponível em: <http://www.revistabula.com/2680-os-10-melhores-poemas-de-manoel-de-barros/>. Acesso em: 30 de jan. de 2019. ${ }^{16}$ BENJAMIN, Walter. Magia e técnica, arte e política: ensaios sobre literatura e história da cultura. São Paulo: Brasiliense, 1994, p. 226.

17 Ibidem.

18 TRAUB; WIESNER, 1975 apud MUELLER, op. cit., p. 101.

${ }^{19}$ ADORNO, Theodor W. Minima Moralia. Reflexionen aus dem beschädigten Leben. In: ADORNO, Theodor W. Gesammelte Schriften, v. 4. Berlim: Suhrkamp Verlag e Digitale Bibliothek, 2003, p. 283.
} 
Adorno, com profunda ascese, recusa-se a apontar positividades, inclusive para a tarefa das Ciências Humanas e Sociais. É na crítica determinada e imanente do modo tradicional de se fazer ciência que a negatividade se amalgama em escrita inversa do seu contrário. Algumas faíscas, vez por outra, sobressaem em meio à crítica determinada, sem que as mesmas possam ser enquadradas dentro de um novo sistema conceitual. Estas são apenas sinais, cifras, fissuras a partir das quais é possível espiar uma positividade, mas as quais tradicionalmente não se teve acesso devido ao sistema conceitual que tudo encobre. As fissuras são importantes porque enaltecem a irredutibilidade da realidade danificada em rupturas, em ruínas. É aí que as centelhas de significado faíscam e quando juntadas aparecem repentinamente e novamente se consomem.

Fazer saltar raios, faíscas, fagulhas de pensamento que iluminam repentinamente a realidade danificada, mostrando uma cor nova na escuridão que tudo envolve sem, contudo, imagear esta positividade, é o próprio da ideia aqui perseguida. Um pensamento correto e justo, que não se coaduna com as injustas condições sociais vigentes, por amor à verdade, não se dá simplesmente como um processo cognitivo abstrato, desvinculado da vida mesma, da realidade destituída de sua potencialidade, uma vez que o próprio pensamento se encontra enredado naquilo que gostaria de transpor. Há de surgir das entranhas, de um gesto corporal, de uma experiência básica que envolve a própria "carne e sangue", e que direciona o olhar, de modo certeiro, às fissuras não totalmente encobertas pelo sistema enclausurador.

\section{A ideia das Ciências Humanas e Sociais é a interpretação}

O olhar das Ciências Humanas e Sociais não tem a função de encontrar vestígios de esperança em meio aos destroços. Sua função é apenas mostrar que o adoecido está doente. A compreensão da vida mesma, das fissuras não completamente encobertas pelo sistema, requer das Ciências Humanas e Sociais uma nova forma interpretativa. Na perspectiva de Adorno, trata-se de

proceder interpretando cada vez mais com a pretensão da verdade, sem possuir nunca uma chave segura de interpretação; que nas figuras-enigma do existente e em seus admiráveis entrelaçamentos não lhe sejam dados mais que fugazes indícios, que se esfumam. ${ }^{20}$

${ }^{20}$ ADORNO, Theodor W. Die Aktualität der Philosophie. ADORNO, Theodor W. Gesammelte Schriften, v. 4. Berlim: Suhrkamp Verlag e Digitale Bibliothek, 2003, p. 334. 
As Ciências Humanas e Sociais deverão proceder interpretando, com pretensão de verdade, sem possuir a chave segura. A interpretação não é definitiva, deve-se proceder sempre interpretando. As Ciências Humanas e Sociais estão condenadas a interpretar a realidade no sentido de ter que, antes de chegar ao final do processo, com um resultado definitivo, recomeçar justamente onde encontram algum resultado. A interpretação, no entanto, não é realizada de qualquer modo, mas sim com "pretensão de verdade". Não se pode entender a pretensão de verdade como tentativa de se chegar à realidade mesma, enquanto adequação do pensamento à realidade. A verdade precisa ser entendida como pretensão de se chegar à "realidade correta e justa", enquanto questionadora das condições sociais injustas vigentes. Afinal, o que importa na interpretação é o assegurar das condições sociais vigentes ou a verdade?

A interpretação da realidade com pretensão de verdade a ser realizada pelas Ciências Humanas e Sociais se dará sem uma chave hermenêutica certa. Não há nenhuma chave hermenêutica segura para se chegar à verdade. Ao invés de uma chave certa, são dados apenas indícios fugazes e evanescentes. A tarefa das Ciências Humanas e Sociais é justamente a interpretação destes indícios fugazes e passageiros. Mas onde podem ser encontradas tais indicações? Talvez na metáfora do tecelão que não ignora os menores dos fios da história.

A história [do pensamento] outra coisa não é que a história de tais entrelaçamentos; por isso lhe são atribuídos poucos "resultados"; por isso continuamente deve-se começar de novo; por isso não pode ela prescindir do mais insignificante fio que o tempo passado entrelaçou e, quem sabe, complete a trama que poderia transformar as cifras em um texto. ${ }^{21}$

Não há, portanto, uma realidade ou um sentido por detrás da mesma que exija uma interpretação por parte das Ciências Humanas e Sociais, mas entrelaçamentos, razão pela qual são dados poucos resultados ou quando estes se apresentam, percebe-se que continuamente é preciso recomeçar, uma vez que o primeiro achado é apenas um sinal que se apresenta como um desafio que é preciso ser decifrado. O que resta é interpretar estes entrelaçamentos, sem negar sequer o mais insignificante fio que o tempo entrelaçou, pois justamente o mais insignificante de todos pode ser aquele que completa a trama, pode ser a chave e a solução do enigma. O que há, portanto, são cifras que desafiam a interpretação e configuram o pensamento como interpretação "do mundo das coisas em seu caráter de cifra" .22

Se as Ciências Humanas e Sociais devem proceder interpretando a realidade danificada, então não poderão ignorar o mínimo detalhe na trama da

\footnotetext{
${ }^{21}$ Ibidem.

${ }^{22}$ MÜLLER-DOOHM, Stefan. En tierra de nadie. Theodor W. Adorno: una biografía intelectual. Barcelona: Herder, 2003, p. 223.

${ }^{23}$ BENJAMIN, Walter. Magia e técnica, arte e política: ensaios sobre literatura e história da cultura. São Paulo: Brasiliense, 1994, p. 223.
} 
história. ${ }^{23}$ Pois é justamente o periférico que se torna mediato e completa a grande teia de fios que a história entrelaçou. Portanto, o dado que exige ser decifrado e interpretado é o-que-está-aí jogado no mundo. Para tal, faz-se necessário iluminar repentinamente e por um instante o-que-está-aí, sem possuir chave segura para tal e sem procurar um sentido predeterminado na realidade. Ao passo que se ilumina a realidade, aquilo que nela se manifesta também se esvanece, de sorte, que esse exercício deve ser de contínua permanência.

A interpretação das Ciências Humanas e Sociais não coincide, de nenhum modo, em encontrar e/ou construir sentido e significado no-que-está-aí. Cabe deixar o-que-está-aí falar por si. Se isso é verdade, então, estabelecer e/ou procurar sentido no-que-está-aí é cometer violência de identificação, ou seja, é não deixar o radicalmente outro se manifestar, é projetar aquilo que se procura no-que-está-aí. A fim de não incorrer nesse tipo de violência, os elementos do existente que compõem as figuras enigmáticas da realidade devem ser agrupados até que falem. Se os elementos devem ser agrupados, têm-se como pressuposto a sua disjunção. Ora, a manifestação do existente é fragmentária e incompleta.

O texto que [...] tem de ler é incompleto, contraditório e fragmentário e grande parte dele pode estar entregue a cegos demônios. Talvez a leitura seja precisamente nossa tarefa, para que lendo aprendamos a conhecer melhor e a banir os poderes demoníacos. ${ }^{24}$

“O conhecimento não possui nenhum de seus objetos completamente. Ele não deve promover o aparecimento do fantasma de um todo" ${ }^{25} \mathrm{~A}$ interpretação dos indícios fugazes que se esfumam aproxima-se da noção de Benjamin sobre a tarefa do cronista dos acontecimentos da história. "O cronista que narra os acontecimentos, sem distinguir entre os grandes e os pequenos, leva em conta a verdade de que nada do que um dia aconteceu pode ser considerado perdido para a história". ${ }^{26}$ Narrar os acontecimentos, sem distinguir entre os grandes e os pequenos, é também a tarefa do cientista humano e social que não considera nada do que um dia aconteceu, mesmo o mais fugaz e passageiro, como sendo perdido para a história. “Lá onde o pensamento se projeta para além daquilo a que, resistindo, ele está ligado, acha-se a sua liberdade. [...]. A necessidade de dar voz ao sofrimento é condição de toda verdade" ${ }^{27}$

\footnotetext{
${ }^{24}$ ADORNO, Theodor W. Die Aktualität der Philosophie. ADORNO, Theodor W. Gesammelte Schriften, v. 4. Berlim: Suhrkamp Verlag e Digitale Bibliothek, 2003, p. 335.

${ }^{25}$ ADORNO, Theodor W. Negative Dialektik. In: ADORNO, Theodor W. Gesammelte Schriften, v. 6. Berlim: Suhrkamp Verlag e Digitale Bibliothek, 2003, p. 25.

${ }^{26}$ BENJAMIN, Walter. Magia e técnica, arte e política: ensaios sobre literatura e história da cultura. São Paulo: Brasiliense, 1994, p. 223.

${ }^{27}$ ADORNO, Theodor W; HORKHEIMER, Max. Dialektik der Aufklärung. In: ADORNO, Theodor W. Gesammelte Schriften, v. 4. Berlim: Suhrkamp Verlag e Digitale Bibliothek, 2003, p. 29.
} 
Quem interpreta, quando procura atrás do mundo dos fenômenos um mundo em si, que lhe serve de base e o sustenta, se comporta como alguém que quisesse procurar no enigma a reprodução de um ser que se encontra detrás, que o enigma reflete, em que se deixa sustentar; enquanto que a função para a solução do enigma é iluminar como um relâmpago a sua figura e fazê-la emergir, e não teimar em ir até o fundo do enigma e assemelhar-se a ele. A autêntica interpretação [...] não aceita um sentido que já se encontra pronto e permanente por detrás da questão, e sim a ilumina repentina e instantaneamente e, ao mesmo tempo, a consome. ${ }^{28}$

Não se trata de encontrar um ser por detrás de um enigma que se exige ser solucionado quando a função da solução de enigmas é justamente o contrário, ou seja, com o encaixe da menor das peças, fazer aparecer a figura a um só golpe, consumindo repentina e instantaneamente a questão que desafiava solução. A autêntica interpretação das Ciências Humanas e Sociais não procura um sentido pronto e permanente, mas faz com que os sinais indecifráveis se transformem em texto, nunca se esquecendo, como já assinalado acima, que o texto a ser lido é "incompleto, contraditório e fragmentário e grande parte dele pode estar entregue a cegos demônios" ${ }^{29}$

As metáforas de Adorno sobre o tecelão que não ignora o menor dos fios e o solucionador de enigma que encaixa a menor das peças e faz saltar, a um só golpe, a solução do mesmo, são análogas e adquirem maior eloquência na aproximação com a metáfora da constituição do mosaico de Benjamin. As metáforas são constitutivas do pensamento de ambos os autores. A tese defendida por Schneider de que em Benjamin "a contradição da linguagem é o ponto focal a ser considerado para a compreensão da atividade filosófica" ${ }^{30}$ também se inscreve para a atividade filosófica de Adorno. O uso de metáforas, de imagens e de conceitos diferenciados para expressar o mesmo conteúdo torna o pensamento de ambos os autores complexo, mas é condição da própria tarefa do pensamento por eles descrita: a solução de enigma num relâmpago e na montagem do mosaico em sua fragmentação caprichosa de partículas.

\section{Considerações finais}

As reflexões apresentadas neste texto nos permitem tecer algumas considerações um tanto quanto fortes sobre a atualidade das Ciências Humanas e Sociais. A perspectiva aqui defendida por meio da interpretação o

\footnotetext{
${ }^{28}$ ADORNO, Theodor W. Die Aktualität der Philosophie. ADORNO, Theodor W. Gesammelte Schriften, v. 4. Berlim: Suhrkamp Verlag e Digitale Bibliothek, 2003, p. 335.

${ }^{29}$ Ibid. p. 334.

${ }^{30}$ SCHNEIDER, Paulo Rudi. A contradição da linguagem em Walter Benjamin. Ijuí: Unijuí, 2008, p. 299.
} 
pensamento de Adorno revela que a reflexão teórica destas ciências não se dá no distanciamento para com a realidade, noção tão cara ao pensamento ocidental como um todo, mas sim é possibilitada por situações determinadas, por contextos espaciais e temporais específicos, desde que realizada a constante rememoração do passado, na perspectiva da experiência de indignação da realidade danificada. "Dar voz ao sofrimento", trazer o mundo danificado para dentro da reflexão destas ciências para, com e a partir dele, pensar a vida, buscando interpretar os emaranhados históricos que a formam, "é condição de toda verdade" ${ }^{31}$ e, portanto, da atualidade das Ciências Humanas e Sociais.

Contudo, não são poucos os críticos de Adorno que apontam para a impossibilidade de seu movimento dialético, justamente por insistir radicalmente na negatividade. Também não são poucos os que veem em Adorno um pessimista radical. Há, neste caso, uma confusão entre pessimismo e negatividade dialética determinada. A desesperança, que paradoxalmente se revela como esperança, somente é percebida por aqueles olhos que recusam se desviar da negatividade que emana da realidade dilacerada. A exigência adorniana de perder-se irreservadamente no objeto requer um pensar menos violento e mais cauteloso; menos impositivo, atento à realidade.

"Os destroços da história contêm, assim, sua possibilidade e sua esperança. Só desde eles pode-se 'preparar o instante', como Adorno vai dizer de Benjamin; o instante que, enigmaticamente, a história pode reverter" ${ }^{32} \mathrm{~A}$ esperança se desprende na resistência à volta da atrocidade. Narrar novamente a história é condição de possibilidade de não se voltar ao horror passado. A não incorporação da história, especialmente do condenado e do violentado, impede a reabilitação do sujeito como humano e deixa abertas possibilidades do retorno da violência. Neste sentido, permitir ao violentado dizer a sua palavra é uma das condições para a atualidade das Ciências Humanas e Sociais.

Enquanto as Ciências da Natureza têm o papel de evitar o aparecimento de fissuras que colocam em jogo a vida de pessoas, as Ciências Humanas e Sociais têm por função privilegiar as fissuras que escapam do enclausuramento do modelo social, especialmente o que é de pouco valor para a indústria cultural. Em outras palavras, cabe às Ciências da Natureza evitar, de todas as formas possíveis, o aparecimento de rachaduras no sistema social, político, cultural, econômico, com a demonstração da impossibilidade de determinado projeto ou, se executado, primando pelo seu melhor desenvolvimento, com menor impacto ambiental, social e cultural. Já o papel das Ciências Humanas e Sociais se constitui em constante exercício

\footnotetext{
${ }^{31}$ ADORNO, Theodor W. Dialética negativa. Rio de Janeiro: Jorge Zahar, 2009, p. 24.

32 MUELLER, Ênio Ronald. Filosofia à sombra de Auschwitz: um dueto com Adorno. São Leopoldo: Sinodal/EST, 2009, p. 193.
} 
de desconfiança, de negação determinada, de crítica implacável, a partir da qual poderá se manifestar uma cor diferente em meio ao acinzentado "reboco" que encobre as fissuras históricas deixadas pela devastadora tempestade que sopra do paraíso terrestre tão almejado pela modernidade e que se chama progresso.

As fissuras histórico-sociais não devem ser encobertas por um pensamento ingênuo que mantém toda a estrutura perfeita, enquanto fachada. Em uma metáfora, o papel da Ciências Humanas e Sociais não é o de rebocar ou pintar a fachada de um prédio que está prestes a ruir. Pelo contrário, precisam se constituir em interpretação audaciosa, que olha de modo suspeito para estas fissuras deixadas pela ordem econômica, cultural e social vigente. Neste sentido, Adorno lança luzes para uma reflexão audaciosa, na medida em que alarga as fissuras histórico-sociais, enaltecendo a irredutibilidade da realidade danificada.

Portanto, a atualidade das Ciências Humanas e Sociais exige um olhar interpretativo analítico que se justifica pelo fato de que a vida humana é muito mais do que a mera obediência ao mercado; de que antes de atender a este mercado é preciso entendê-lo. Ressalta-se, portanto, que as Ciências Humanas e Sociais contribuem de modo específico e próprio para com o desenvolvimento humano, social, político e educacional na medida em que ampliam as visões de mundo, denunciam as injustiças sociais, situam o sujeito na história e no contexto social e apontam para a possibilidade de um outro mundo.

\section{Referências}

ADORNO, Theodor W. Die Aktualität der Philosophie. ADORNO, Theodor W. Gesammelte Schriften, v. 4. Berlim: Suhrkamp Verlag e Digitale Bibliothek, $2003 f$.

ADORNO, Theodor W. Die Idee der Naturgeschichte. In: ADORNO, Theodor W. Gesammelte Schriften, v. 1. Berlim: Suhrkamp Verlag e Digitale Bibliothek, 2003g.

ADORNO, Theodor W. Dialética negativa. Rio de Janeiro: Jorge Zahar, 2009.

ADORNO, Theodor W. Minima Moralia. Reflexionen aus dem beschädigten Leben. In: ADORNO, Theodor W. Gesammelte Schriften, v. 4. Berlim: Suhrkamp Verlag e Digitale Bibliothek, 2003d.

ADORNO, Theodor W. Negative Dialektik. In: ADORNO, Theodor W. Gesammelte Schriften, v. 6. Berlim: Suhrkamp Verlag e Digitale Bibliothek, 2003e.

ADORNO, Theodor W. Noten zur Literatur: Blochs Spuren. In: ADORNO, Theodor W. Gesammelte Schriften, v. 11. Berlim: Suhrkamp Verlag e Digitale Bibliothek, 2003c.

ADORNO, Theodor W. Noten zur Literatur: Henkel, Krug und frühe Erfahrung. In: ADORNO, Theodor W. Gesammelte Schriften, v. 11. Berlim: Suhrkamp Verlag e Digitale Bibliothek, 2003b. 
ADORNO, Theodor W; HORKHEIMER, Max. Dialektik der Aufklärung. In: ADORNO, Theodor W. Gesammelte Schriften, v. 4. Berlim: Suhrkamp Verlag e Digitale Bibliothek, 2003.

BARROS, Manoel de. Uma didática da invenção. Disponível em: <http://www.revistabula.com/2680-os-10-melhores-poemas-de-manoel-de-barros/>. Acesso em: 30 de jan. de 2019.

BENJAMIN, Walter. Magia e técnica, arte e política: ensaios sobre literatura e história da cultura. São Paulo: Brasiliense, 1994.

BLOCH, Ernst. O princípio esperança. Trad. Nélio Schneider e Werner Fucks. Rio de Janeiro, Contraponto, 2005.

CERTEAU, Michel de. A invenção do cotidiano: artes de fazer. Petrópolis: Vozes, 1994.

MUELLER, Ênio Ronald. Filosofia à sombra de Auschwitz: um dueto com Adorno. São Leopoldo: Sinodal/EST, 2009.

MÜLLER-DOOHM, Stefan. En tierra de nadie. Theodor W. Adorno: una biografía intelectual. Barcelona: Herder, 2003.

SCHNEIDER, Paulo Rudi. A contradição da linguagem em Walter Benjamin. Ijuí: Unijuí, 2008.

TIEDEMANN, Rolf. Editorische Nachbemerkung. In: ADORNO, Theodor W. Gesammelte Schriften, v. 1. Berlim: Suhrkamp Verlag e Digitale Bibliothek, 2003.

WIGGERSHAUS, Rolf. Escola de Frankfurt: história, desenvolvimento teórico, significação política. Rio de Janeiro: Difeel, 2002.

\section{Fábio César Junges}

Rua Antunes Ribas, 2045, Apto. 301

98801-630 Santo Ângelo - RS - Brasil

E-mail: fabiocesarjunges@unicruz.edu.br

Antonio Escandiel de Souza

E-mail: asouza@unicruz.edu.br

Vânia Maria Abreu de Oliveira

E-mail: vfreitas@unicruz.edu.br 